\title{
Multiple vegetating tumors on the upper left limb
}

\author{
Anissa Zaouak', Leila Bouhajja', Wafa Koubaa², Houda Hammami', Samy Fenniche'
}

\author{
${ }^{1}$ Department of Dermatology, Habib Thameur Hospital, University of Tunis El Manar, Tunis, Tunisia, ${ }^{2}$ Department of \\ Pathology, Habib Thameur Hospital, University of Tunis El Manar, Tunis, Tunisia
}

Corresponding author: Dr. Anissa Zaouak, E-mail: anissa_zaouak@yahoo.fr

Sir,

We report the case of a 54-year-old male without a significant medical history presenting to our department for multiple vegetating tumors located on the upper left limb seen for the past two months. A dermatological examination revealed multiple vegetating tumors confluent on the left arm with other well-circumscribed tumors on the left forearm (Fig. 1). There was no axillary lymphadenopathy. Laboratory values, including the level of lactate dehydrogenase (LDH) and the complete blood cell count, were within normal limits. Computed tomography of the thoracoabdominal region was normal, and there was no evidence of a systemic involvement. A skin biopsy of the vegetating tumor was performed, revealing an infiltration of the dermis extending to the deep dermis with large lymphoid cells (Fig. 2a). The tumor cells were large, pleomorphic, and anaplastic with round, irregularly shaped nuclei and abundant pale cytoplasm (Fig. 2b). The tumor cells expressed CD2, CD4 and, weakly, CD3. More than $75 \%$ of the tumor cells expressed CD30 (Fig. 2c). The tumor cells were also negative for EMA (epithelial membrane antigen) and ALK (anaplastic lymphoma kinase). Combined clinical and histopathological findings allowed us to confirm the diagnosis of primary cutaneous anaplastic largecell lymphoma (PCALCL). The patient received radiotherapy treatment with a favorable outcome. A 4-year follow-up revealed no recurrence.

Herein, we report a case of primary cutaneous anaplastic large-cell lymphoma (PCALCL), which is characterized by large $\mathrm{T}$ cells with prominent nuclear polymorphism and expression of CD30 by more than $75 \%$ of the tumor cells [1]. In this particular type of T-cell lymphoma, there is, as in our case, a male predominance, also usually affecting elderly patients in the sixth decade of their life. Clinically, it can manifest itself as a solitary tumor or grouped nodules in an anatomical location with a rapid tumor growth. The lesions are often vegetating, as in our patient, but can also be ulcerated [2]. A location on the extremities, as in our case, represents the preferred site of PCALCL. The differential diagnosis includes mainly lymphomatoid papulosis type $\mathrm{C}$, the tumor stage of mycosis fungoides, cutaneous metastases from an internal malignancy, systemic large-cell lymphoma, and cutaneous B-cell lymphoma. The main differential diagnosis is lymphomatoid papulosis, with which PCALCL shares clinical and histological features. The differences arise upon close clinical examination and medical history taking. In fact, the lesions of lymphomatoid papulosis are smaller and more diffuse, and do not progress with time [2].

Besides, histopathology and an immunohistochemical study are the key to the diagnosis of PCALCL.

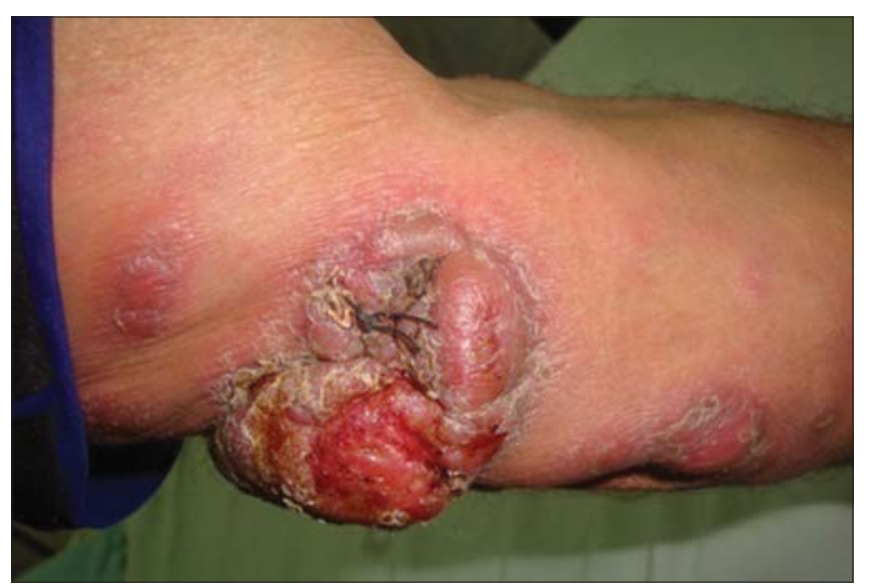

Figure 1: Multiple vegetating tumors on the left arm.

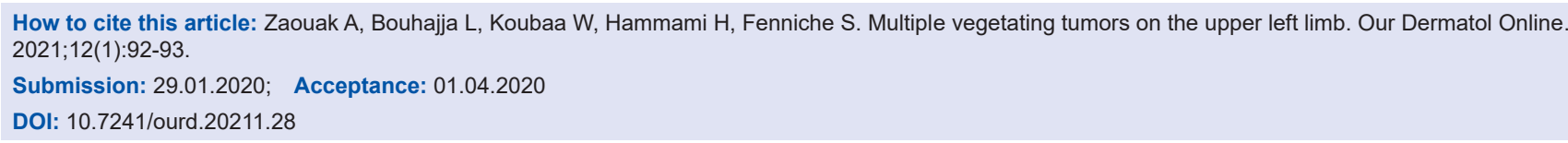



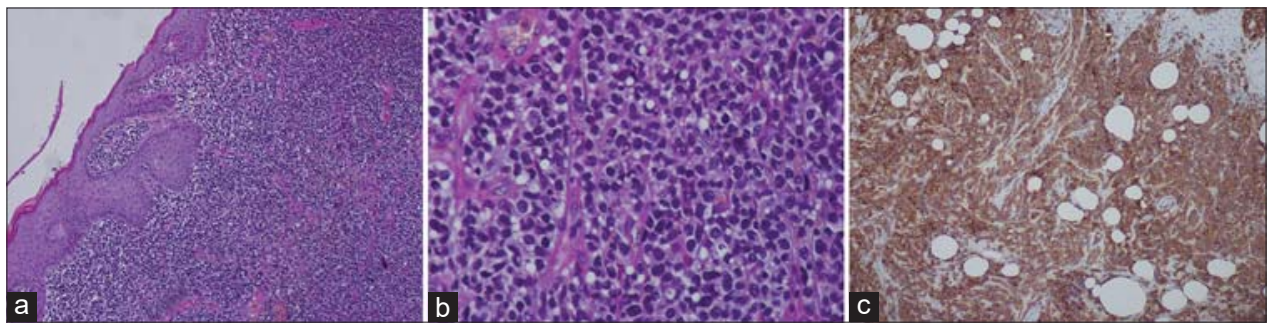

Figure 2: (a) Dense lymphocytic infiltration of the dermis (H\&E, $\times 40)$. (b) Large pleomorphic and anaplastic lymphoid cells (H\&E, $\times 100)$. (c) CD30 stain highlights the large and anaplastic tumor cells.

Typically, the tumor manifests itself as circumscribed nodular infiltrate of an arrangement of large lymphoid cells extending to the deep dermis, with tumor cells often pleomorphic, anaplastic, with round, irregularly shaped nuclei and abundant pale cytoplasm [3]. Epidermotropism is usually absent. The characteristic feature of PCALCL is expression of CD30 by at least $75 \%$ of its tumor cells, as defined by the WHO classification [4]. Treatment relies mainly on surgical excision of the tumors and radiotherapy for solitary and grouped lesions at a dose of 20 Gy. Chemotherapy is advised for extracutaneous tumors spread beyond locoregional lymph nodes. This type of lymphoma typically gives a good prognosis with a 5 -year survival rate of $90 \%$ [4].

In summary, primary cutaneous anaplastic largecell lymphoma (PCALCL) is both a diagnostic and a therapeutic challenge. Our case highlights the importance of clinicopathological correlation and the importance of early diagnosis and treatment to avoid disease progression and unnecessary aggressive treatment modalities. However, even in the presence of a good prognosis, long-term follow-ups are necessary.

\section{Consent}

The examination of the patient was conducted according to the principles of the Declaration of Helsinki.

The authors certify that they have obtained all appropriate patient consent forms, in which the patients have given consent for images and other clinical information to be included in the journal. The patients understand that their names and initials will not be published and due effort will be made to conceal their identity, but that anonymity cannot be guaranteed.

\section{REFERENCES}

1. Prieto-Torres L, Rodriguez-Pinilla SM, Onaindia A, Ara M, Requena L, Piris MÁ. CD30-positive primary cutaneous lymphoproliferative disorders: molecular alterations and targeted therapies. Haematologica. 2019;104:226-35.

2. Brown RA, Fernandez-Pol S, Kim J. Primary cutaneous anaplastic large cell lymphoma. J Cutan Pathol. 2017;44:570-77.

3. Kempf W. A new era for cutaneous CD30-positive T-cell lymphoproliferative disorders. Semin Diagn Pathol. 2017;34:22-35.

4. Kempf W, Kerl K, Mitteldorf C. Cutaneous CD30-positive T-cell lymphoproliferative disorders-clinical and histopathologic features, differential diagnosis, and treatment. Semin Cutan Med Surg. 2018;37:24-9.

Copyright by Anissa Zaouak, et al. This is an open access article distributed under the terms of the Creative Commons Attribution License, which permits unrestricted use, distribution, and reproduction in any medium, provided the original author and source are credited.

Source of Support: Nil, Conflict of Interest: None declared. 